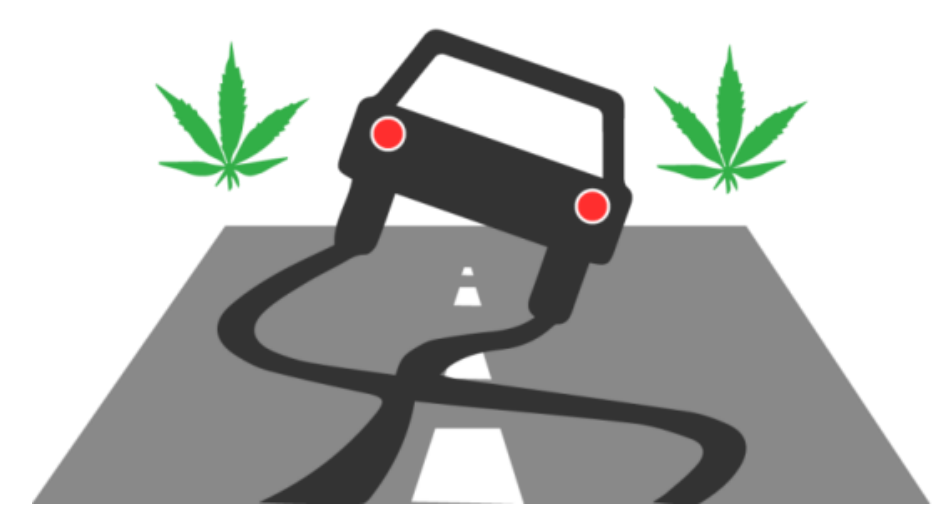

\title{
A Rapid Response Electrochemical Biosensor for Detecting THC In Saliva
}

Shalini Prasad, Ph.D.

Department of Bioengineering, The University of Texas at Dallas,

Richardson, TX 75080, USA. 


\section{Background about THC}

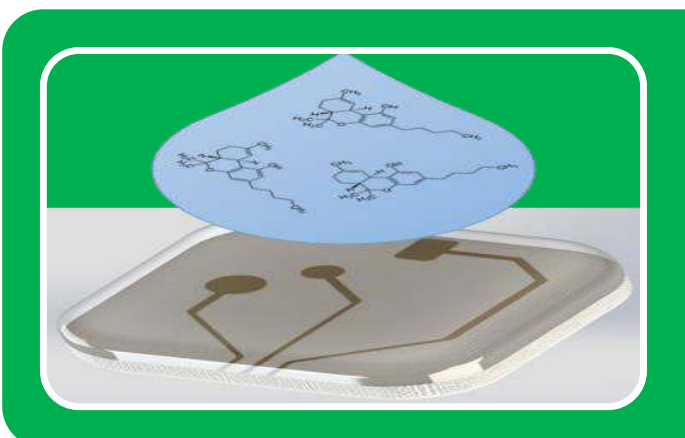

Methodology

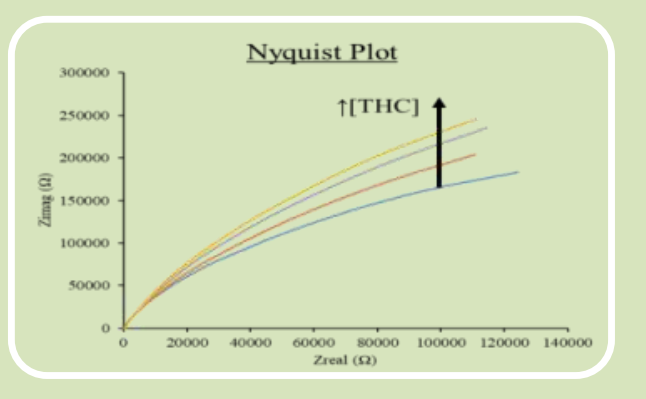

Experimental Results 


\section{Marijuana and Tetrahydrocannabinol (THC)}

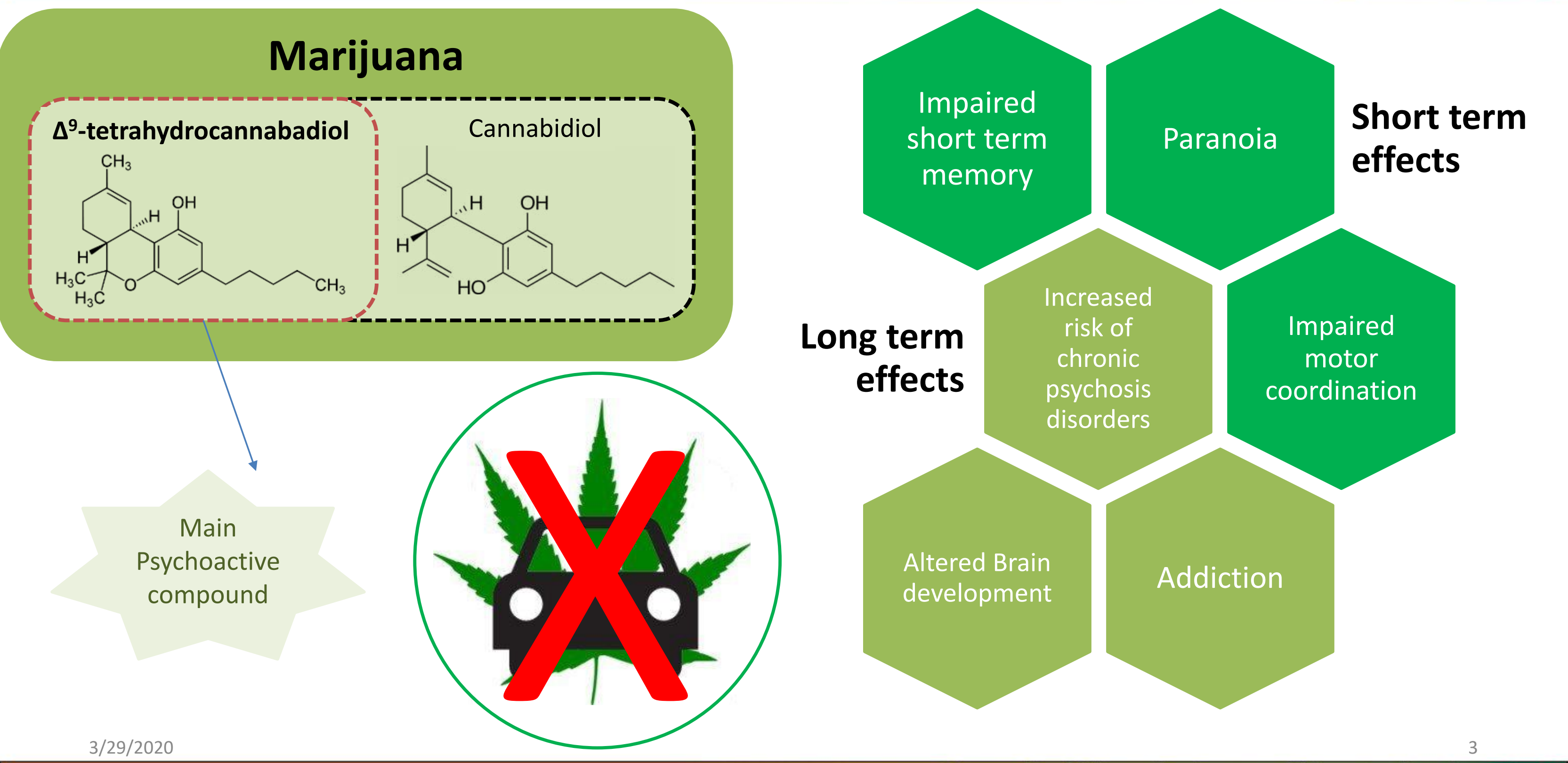




\section{Significance of detection}
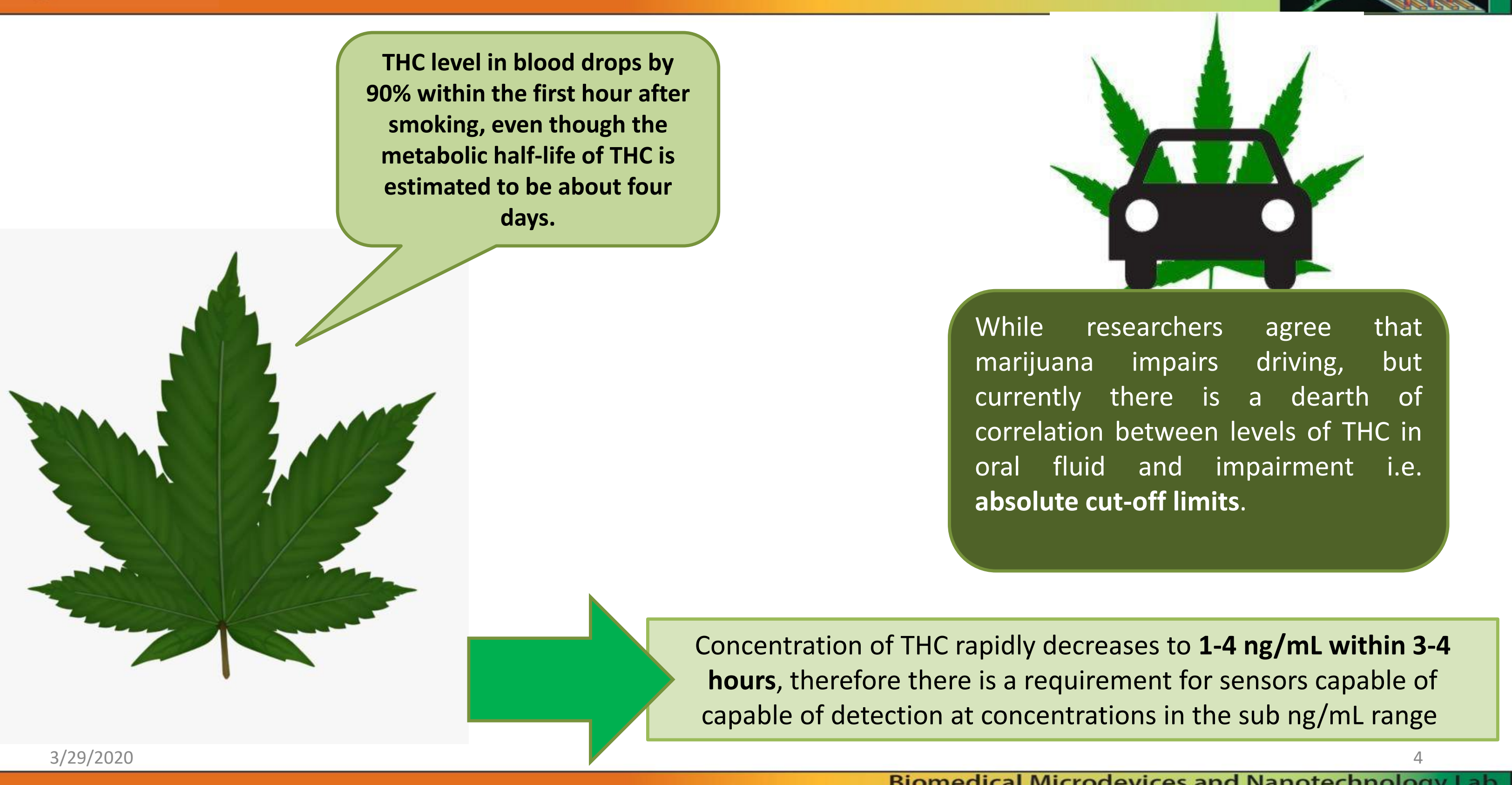

Concentration of THC rapidly decreases to $1-4 \mathrm{ng} / \mathrm{mL}$ within 3-4 hours, therefore there is a requirement for sensors capable of capable of detection at concentrations in the sub $\mathrm{ng} / \mathrm{mL}$ range 


\section{HAIR}

\section{semi-intrusive}

Determine usage pattern Dependent on hair length Storage @ room temperature

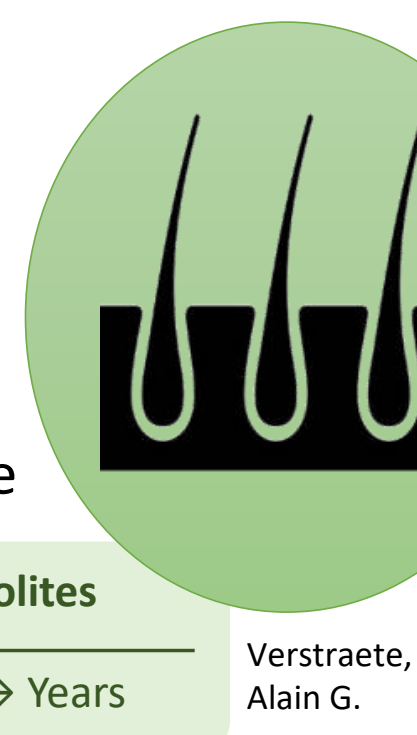

\section{Metabolites}

3 days $\rightarrow$ Years
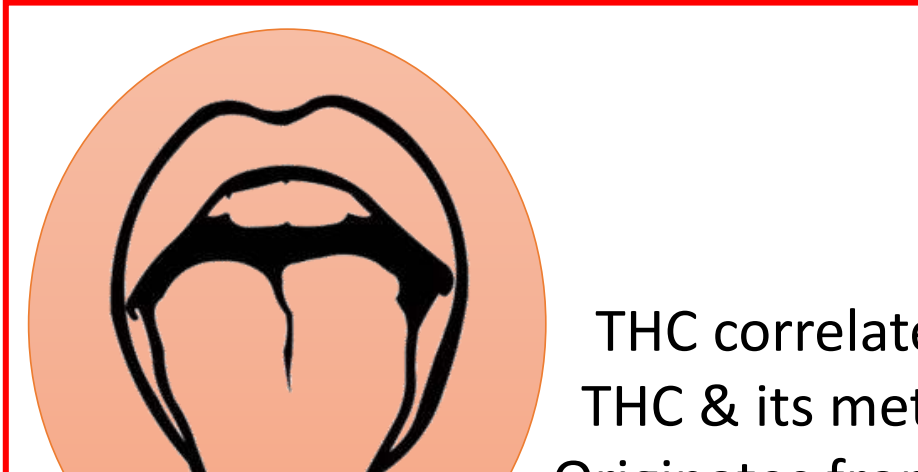

SALIVA

THC correlates to impairment THC \& its metabolites present

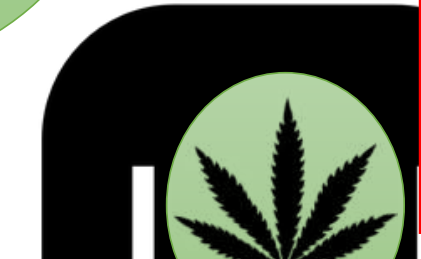

least intrusive Originates from oral mucosa depots

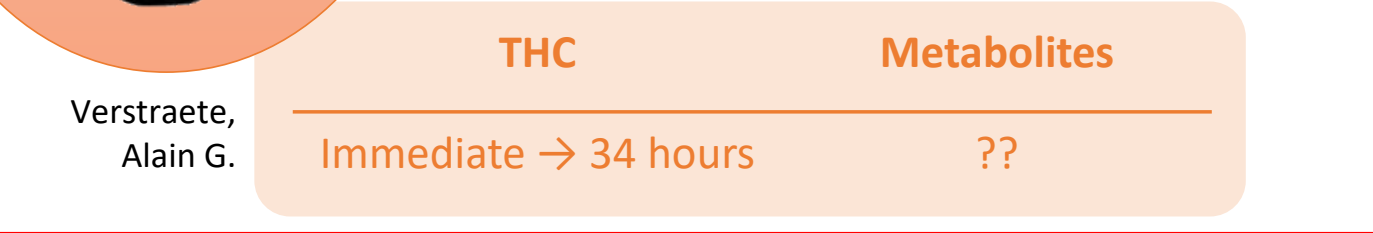

\section{BLOOD}

most intrusive

Most accurate measurement THC \& metabolites present Standard for DUI investigations

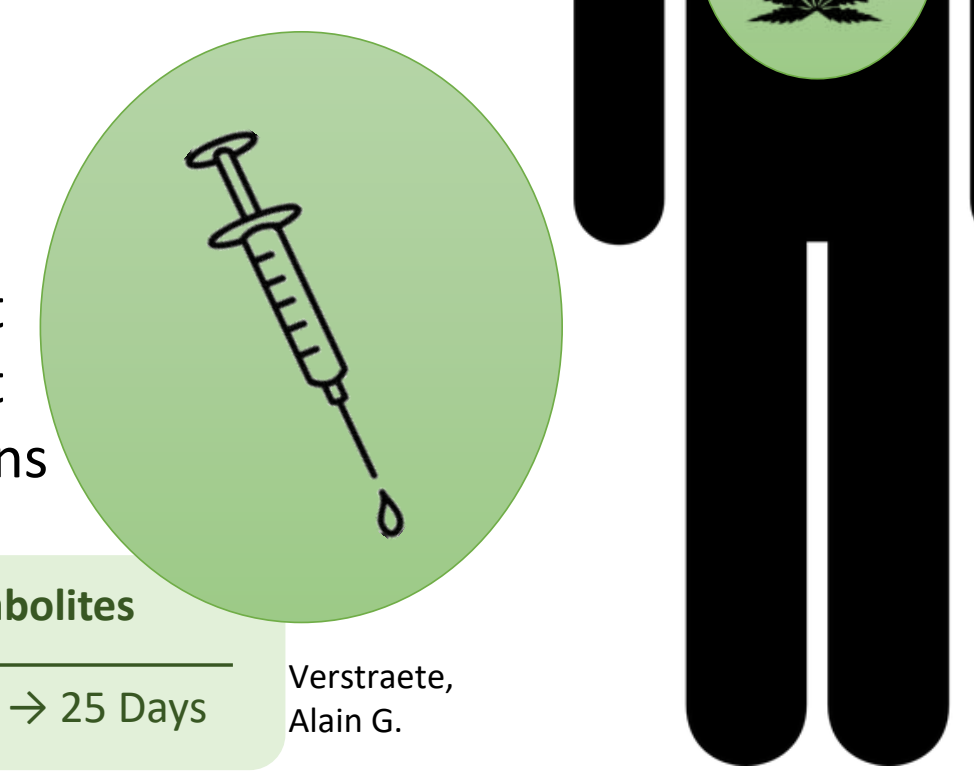

\section{URINE} intrusive

Rapid tests: $\uparrow$ false (+) Only metabolites present Usage affect results

\begin{tabular}{|c|c|}
\hline THC & Metabolites \\
\hline 3 minutes $\rightarrow 5$ hours & Minutes $\rightarrow 25$ Days \\
\hline
\end{tabular}


Average oral fluid to

blood concentration

ratio for $\triangle^{9}$-THC: 1.2
Threshold limits for Thc in blood/saliva:

$0.5-25 \mathrm{ng} / \mathrm{mL}$

- Substance Abuse and Mental Health Services Administration (SAMHSA, Analytes and Their Cutoffs, Federal Register, November 25, 2008 (73 FR 71858), Section 3.4.

- Washington State,Liquor and Cannabis Board- THC limits in blood (DUI).

- Colorado State, Department of Transportation-Cannabis and Driving cut-off limits.

- Drummer OH. Drug testing in oral fluid. Clin Biochem Rev. 2006;27(3):147-159.

- D. Gieringer - Feb 2017 - Vsn 2 Feb 25, Cal NORML

- Phillips, J. A. et al. (2015) 'Marijuana in the Workplace: Guidance for Occupational Health Professionals and Employers: Joint Guidance Statement of the American Association of Occupational Health Nurses and the American College of Occupational and Environmental Medicine', Workplace Health \& Safety, 63(4), pp. 139-164. doi: 10.1177/2165079915581983. 


\section{Sensor Characterization}

A) Sensor Schematic

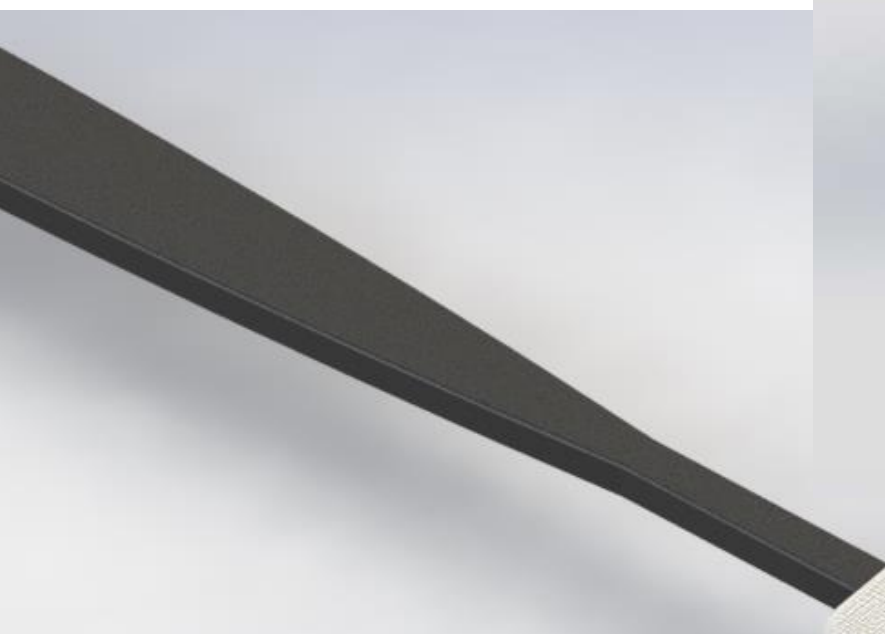

B)
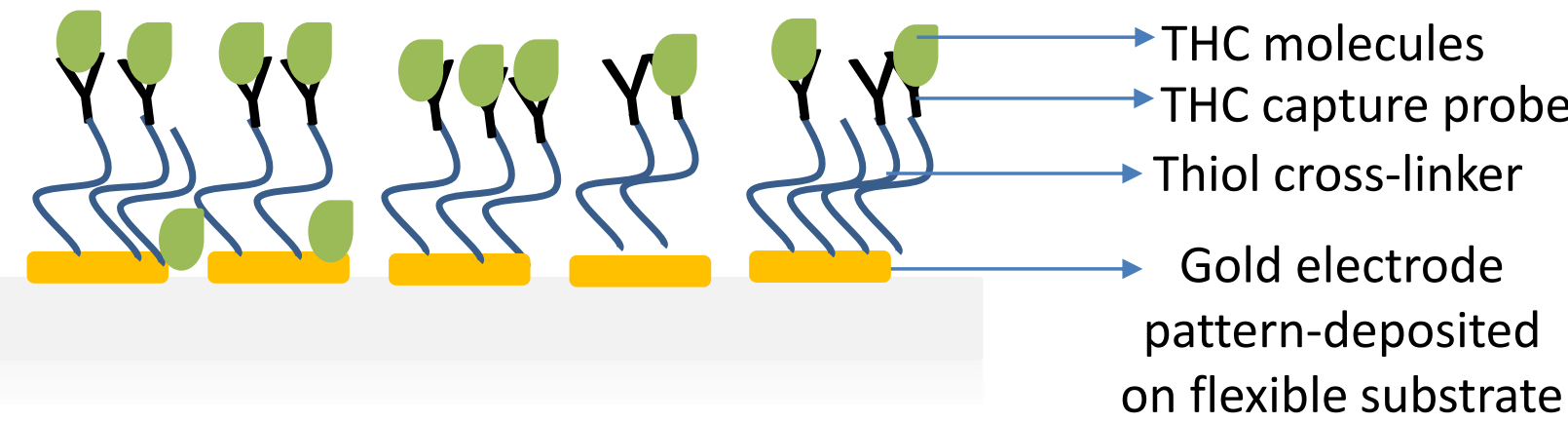

layer

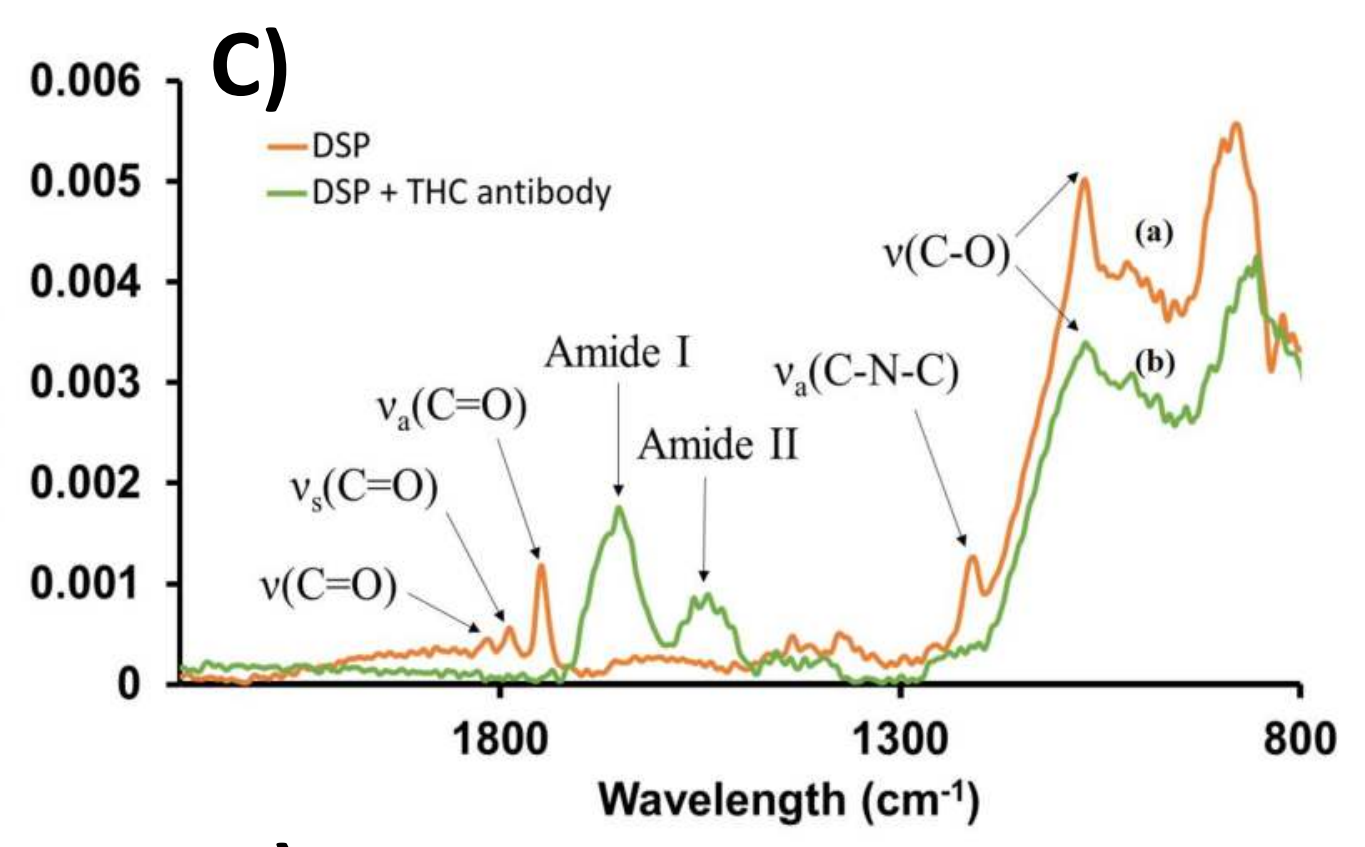

(a)

D)

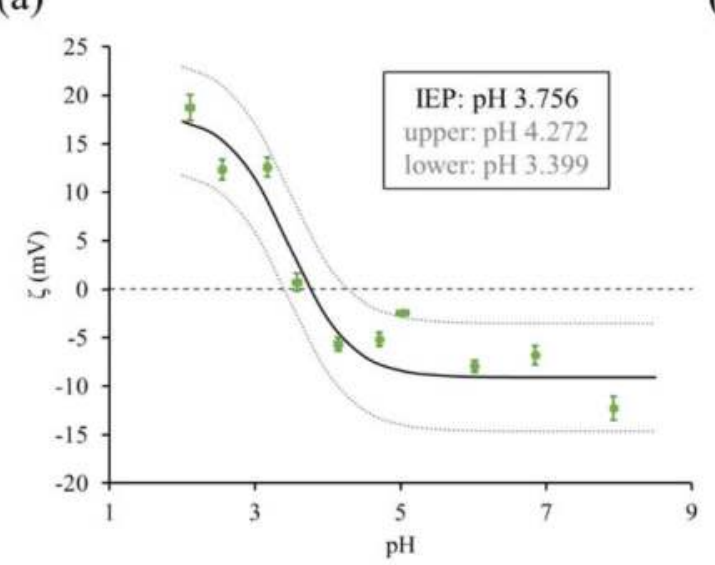

(b)

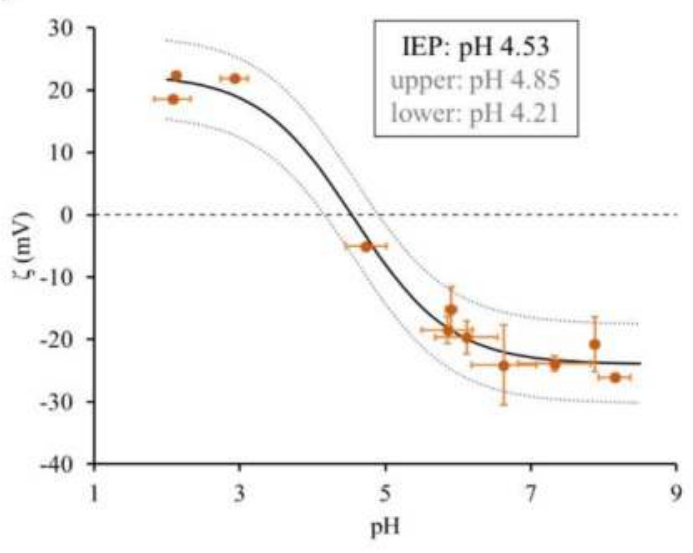




\section{Functional Diagram-Sensor Platform}

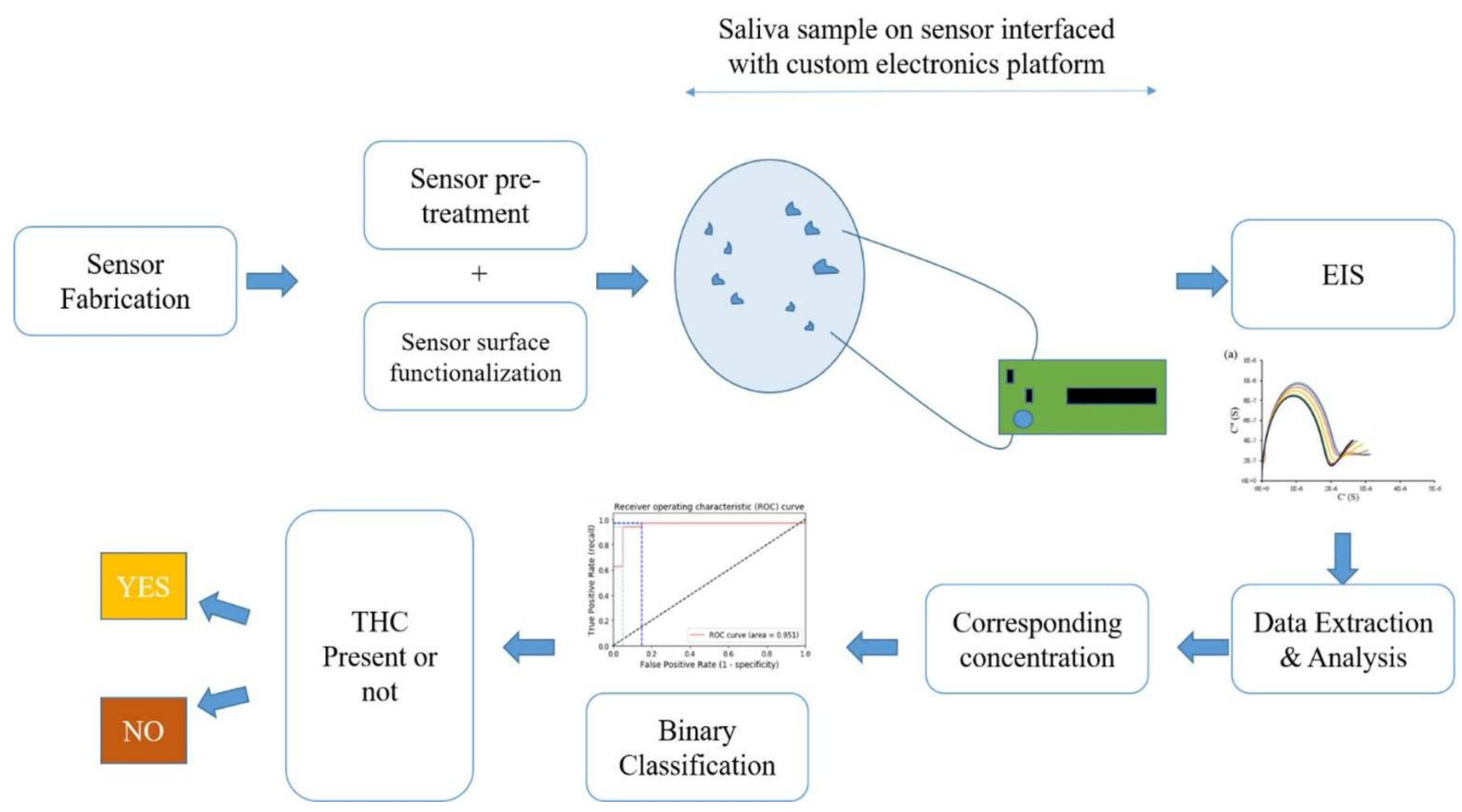




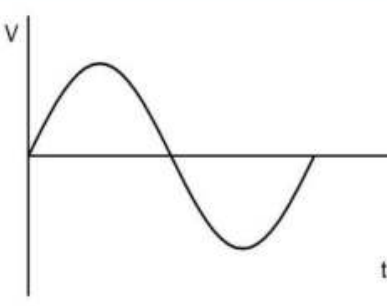

Electrochemical

Impedance

spectroscopy

(EIS)
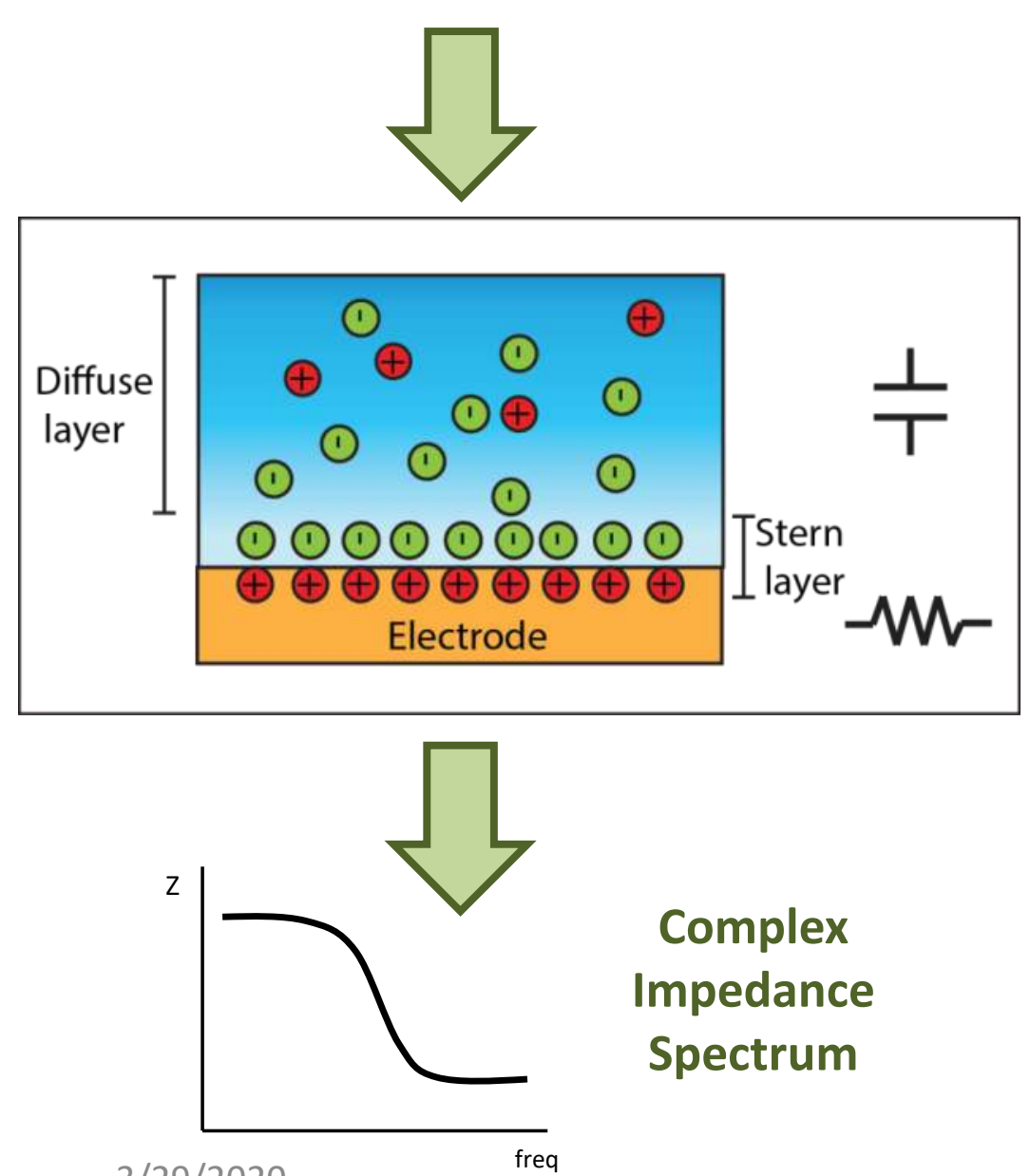

Complex Impedance Spectrum
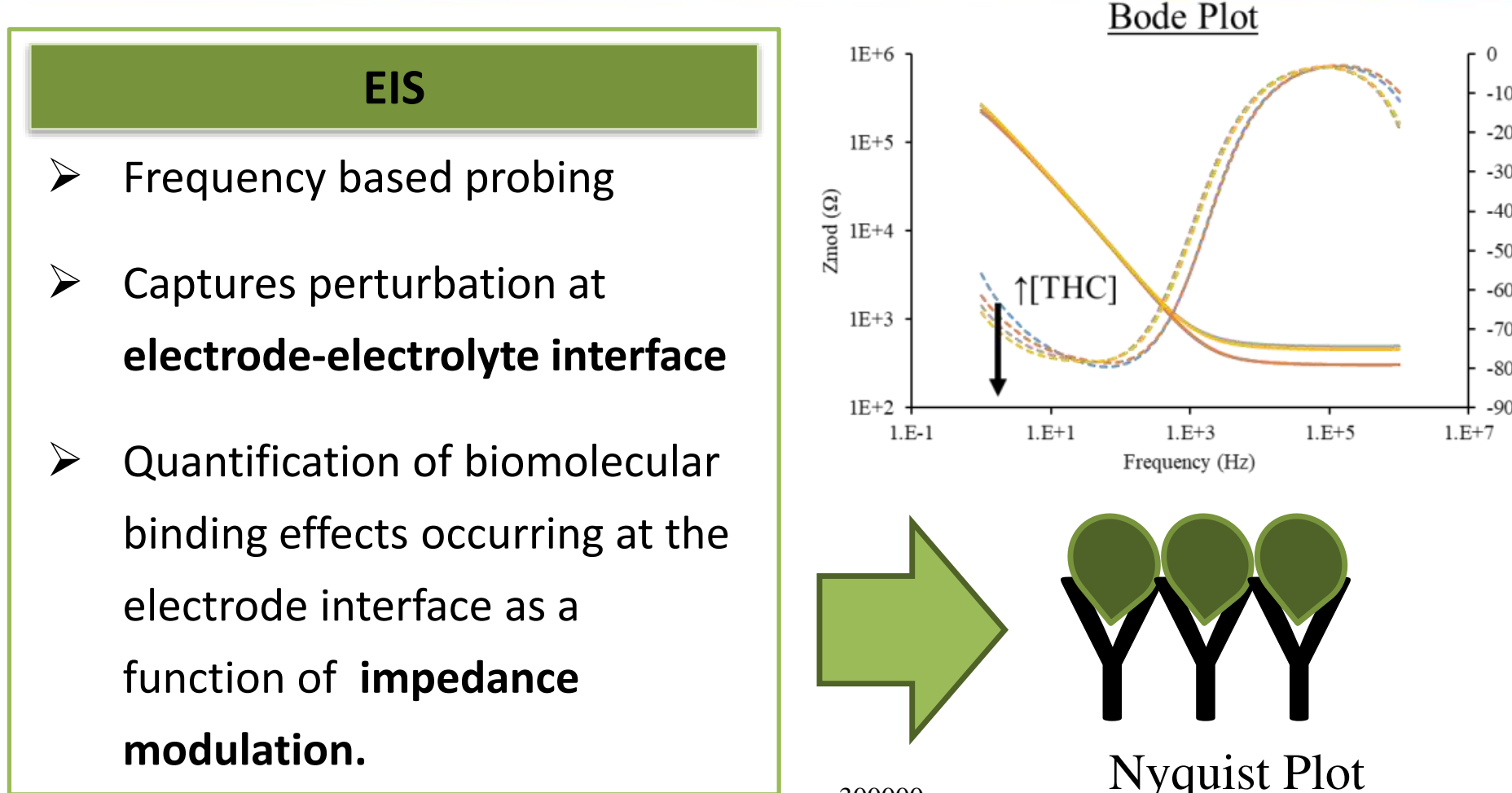

$\underline{\text { Nyquist Plot }}$

Complex Impedance Calculation:

$$
Z=\frac{V_{\text {in }}}{I_{\text {out }}}=\frac{V \sin (\omega t)}{I \sin (\omega t+\phi)}
$$

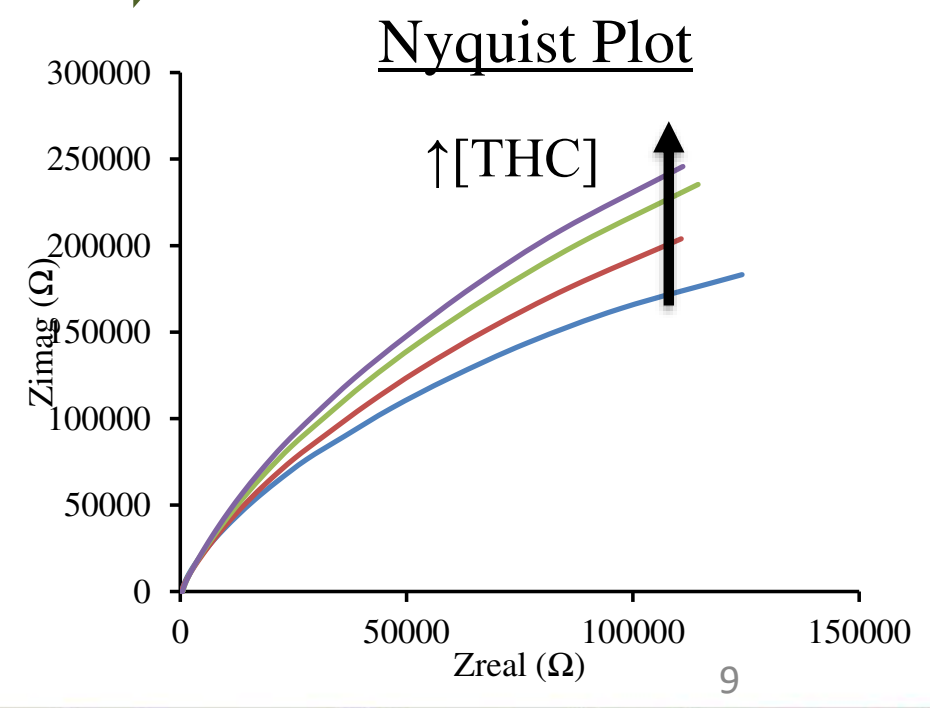


(a)

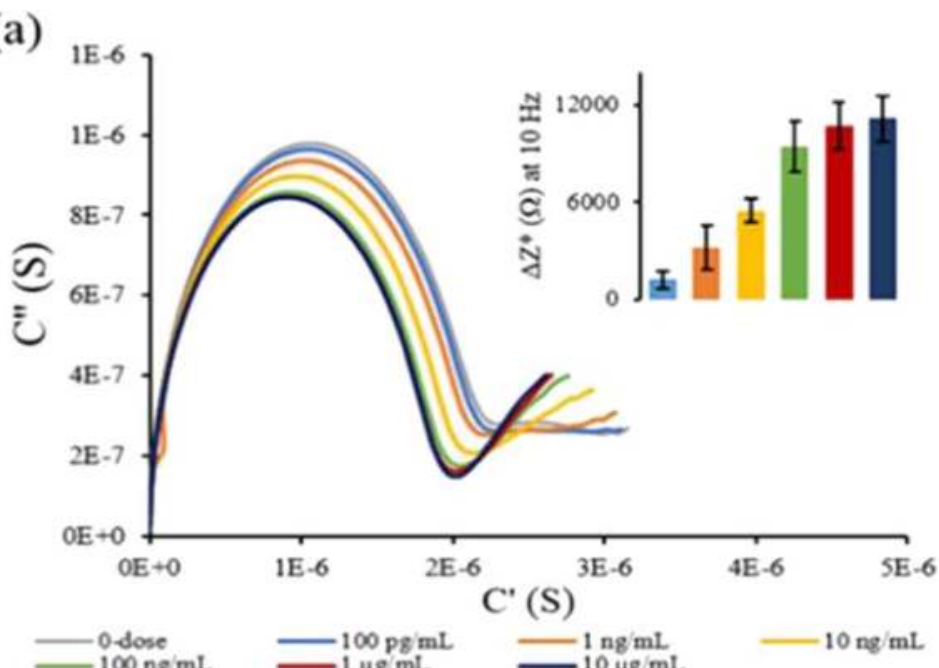

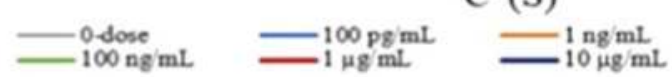

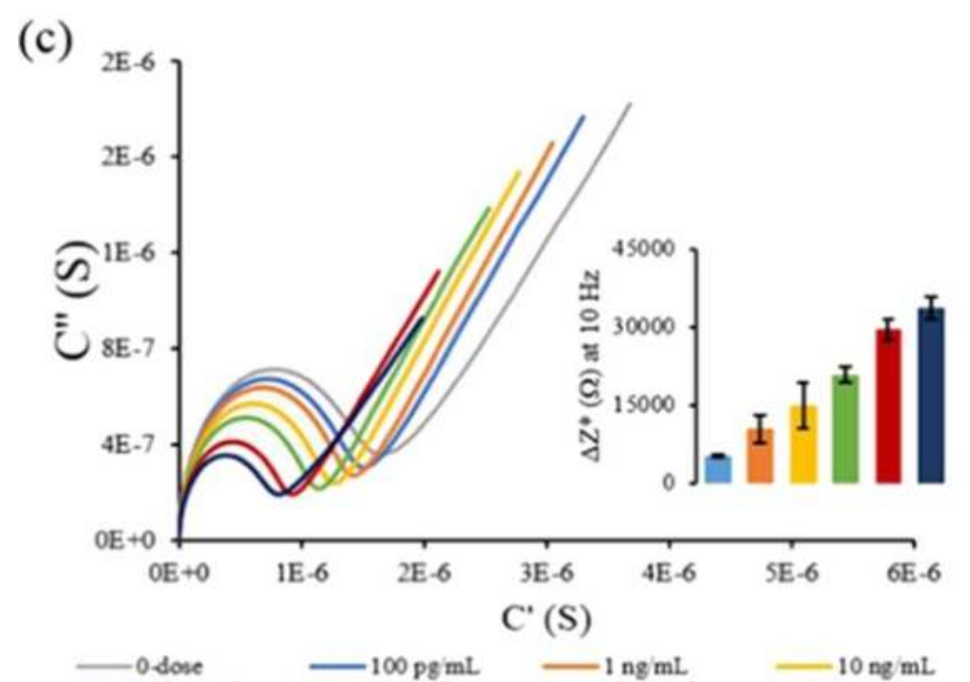

(b)

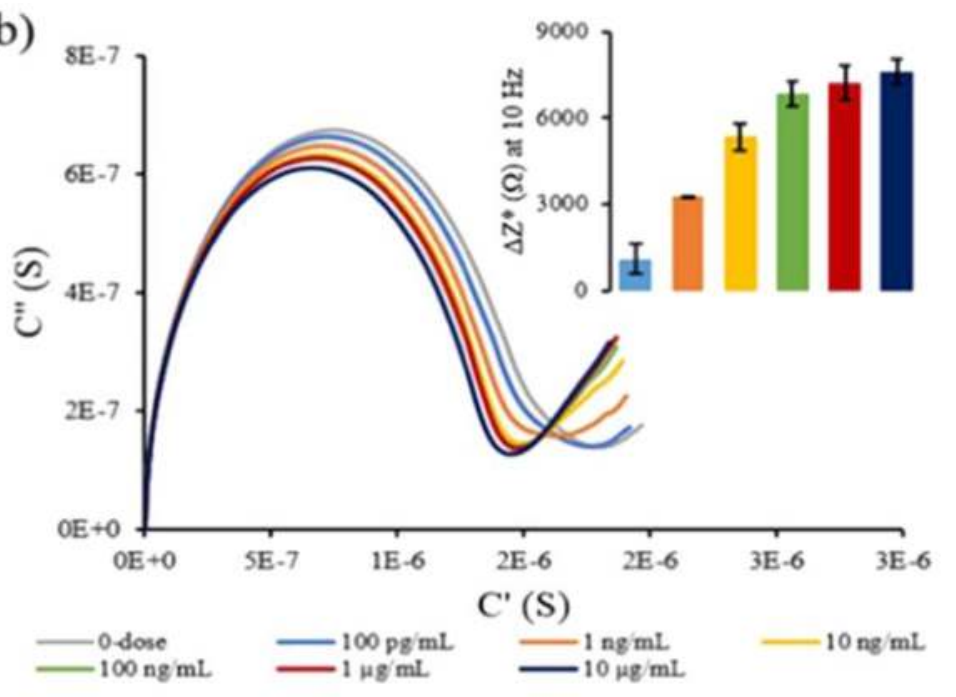

(d)

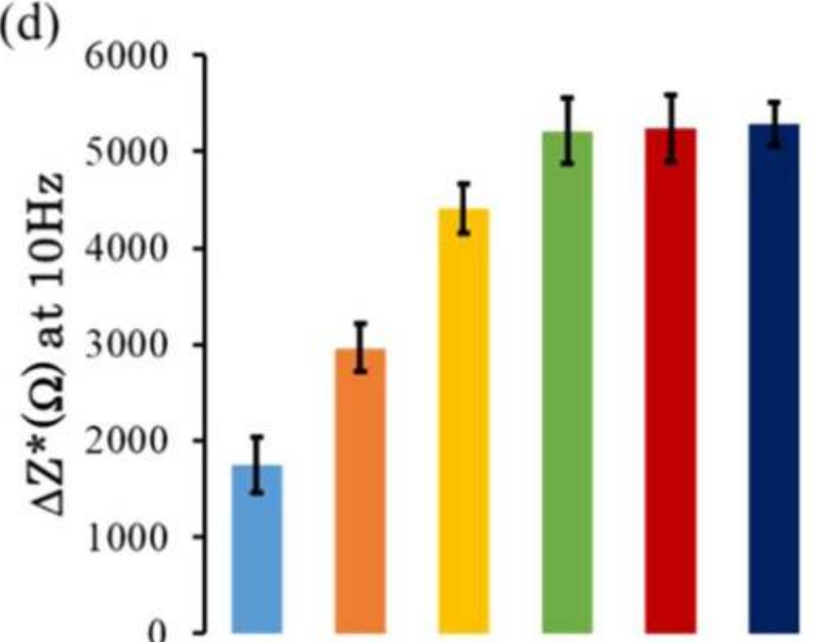

\section{Broad Takeaways:}

- Dose dependent impedance response observed across all sample groups (PBS, Synthetic saliva (pH 4,6), Human saliva).

- For human saliva- Linear dynamic range: $100 \mathrm{pg} / \mathrm{mL}$ to $100 \mathrm{ng} / \mathrm{mL}$

- Limit of Detection (LoD): $100 \mathrm{pg} / \mathrm{mL}$

- Within the dynamic range, the impedance changes are significantly distinguishable from each other.

= $1 \mathrm{ng} / \mathrm{mL}$

$=10 \mathrm{ng} / \mathrm{mL}$

$=100 \mathrm{ng} / \mathrm{mL}$

- $1 \mathrm{ug} / \mathrm{mL}$

- $10 \mathrm{ug} / \mathrm{mL}$

- $4 \mathrm{ng} / \mathrm{mL}$ which is set as the oral fluid drug screening cut-off limit as per SAMSHA guidelines can be effectively screened using this platform. 


\section{Binary Classification model for THC detection}

\section{Objective}

Train a model to categorize our samples as THC (+) or THC (-)

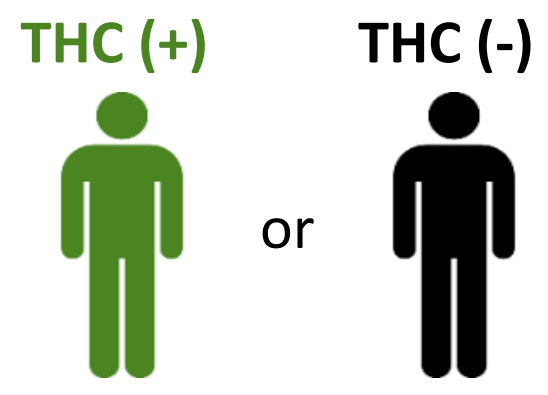

\section{Insight}

- Supervised Learning implies we are given known samples that we then label to train our classifier

- Classification algorithms divide data into subsets in order to verify model accuracy

\section{- Training set}

- Validation (Test) set

- Feature Engineering and pre-processing of data can improve model accuracy and speed

\section{Model Building}

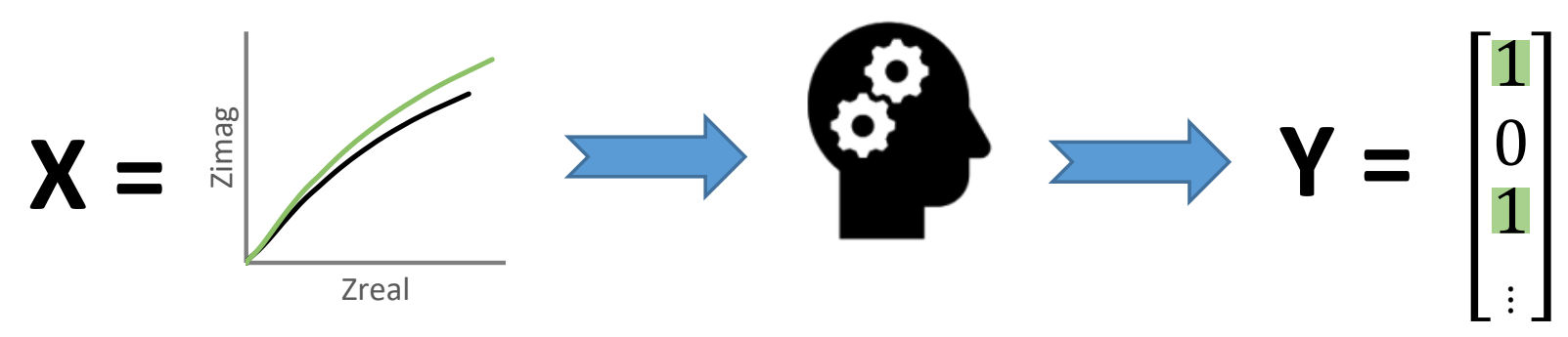

In the model building stage we feed the algorithm our input frequency spectrums and our training set with labels: $\operatorname{THC}(+)=1 \& \operatorname{THC}(-)=0$

The model then looks for the best way to split the inputs between our samples labelled ' 1 ' \& ' 0 '

\section{Model Testing}

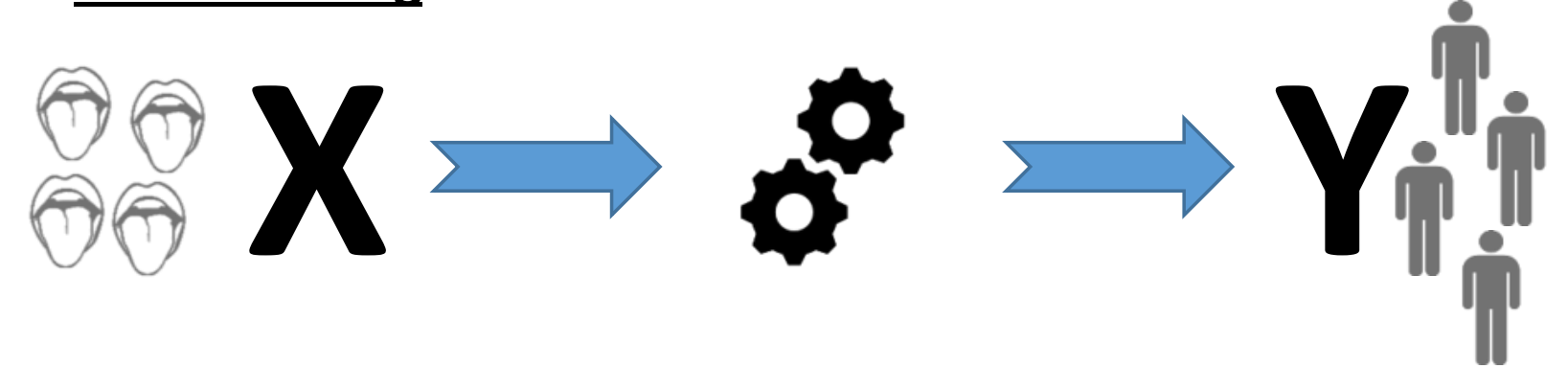

In the model testing stage we deploy the algorithm on 'unseen' data from the validation set to predict the labels, then we compare to the actual result 
Binary Classification Model Performance

- Accuracy: How often is the classifier correct?

$$
(T P+T N) / \text { total }
$$

- Misclassification Rate: How often is the classifier wrong?

$$
(F P+F N) / \text { total }
$$

(TP-True positive, TN-True negative, FP-False positive, FN-False negative)

\section{Confusion Matrix}

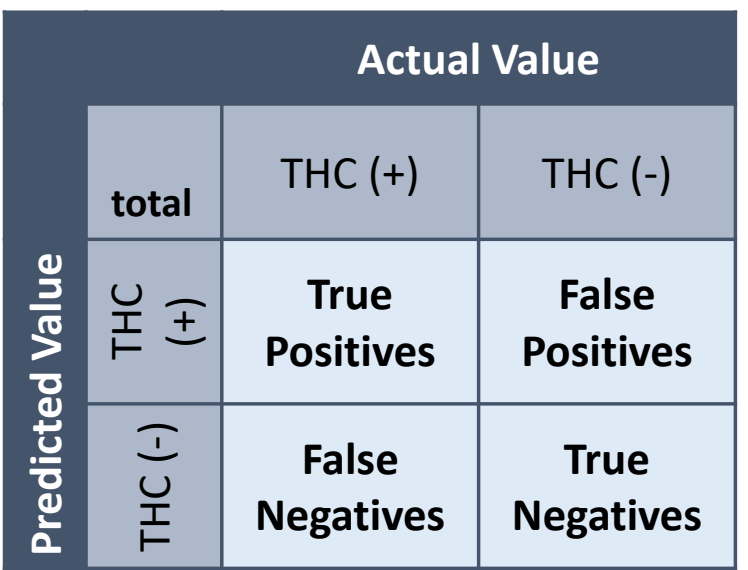

Receiver Operator Characteristics

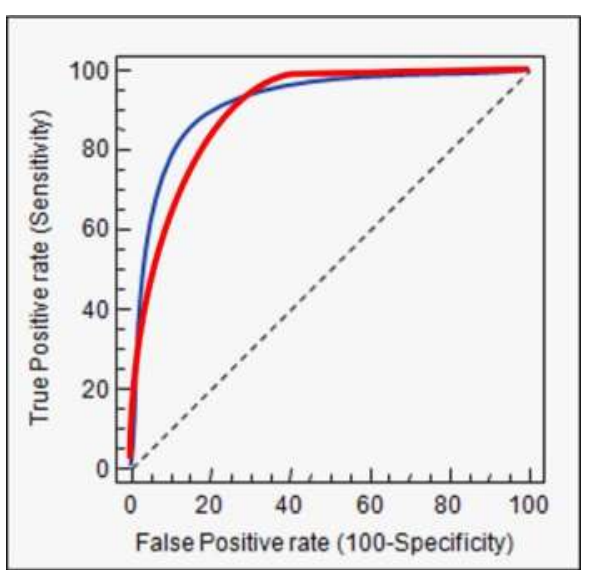

Optimized feature and frequency selection

- Based on fast correlation based filter (FCBF), change in imaginary impedance ( $\mathrm{dz}$ ") with respect to the antibody measurement at $9.9 \mathrm{~Hz}$ was selected as the best feature for separating the data by class ( $\mathrm{THC}+/-$ )

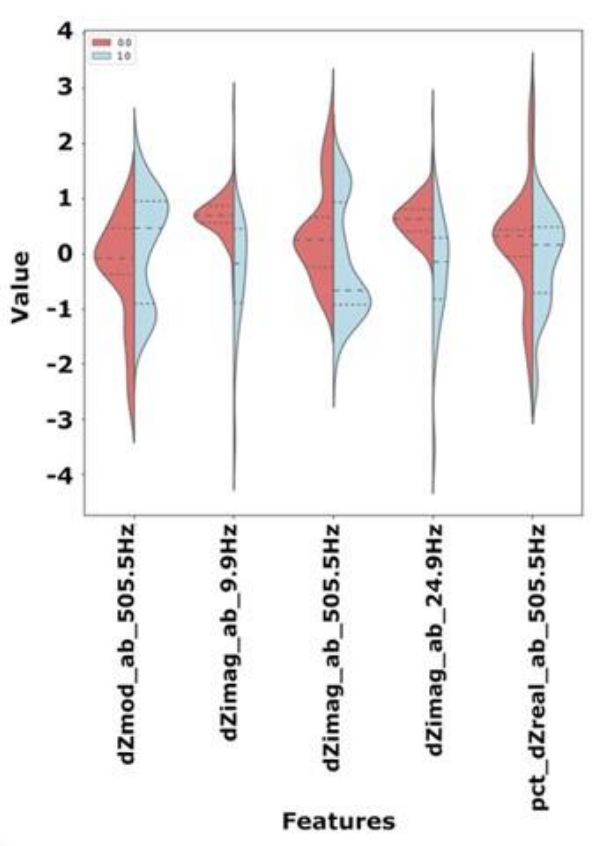

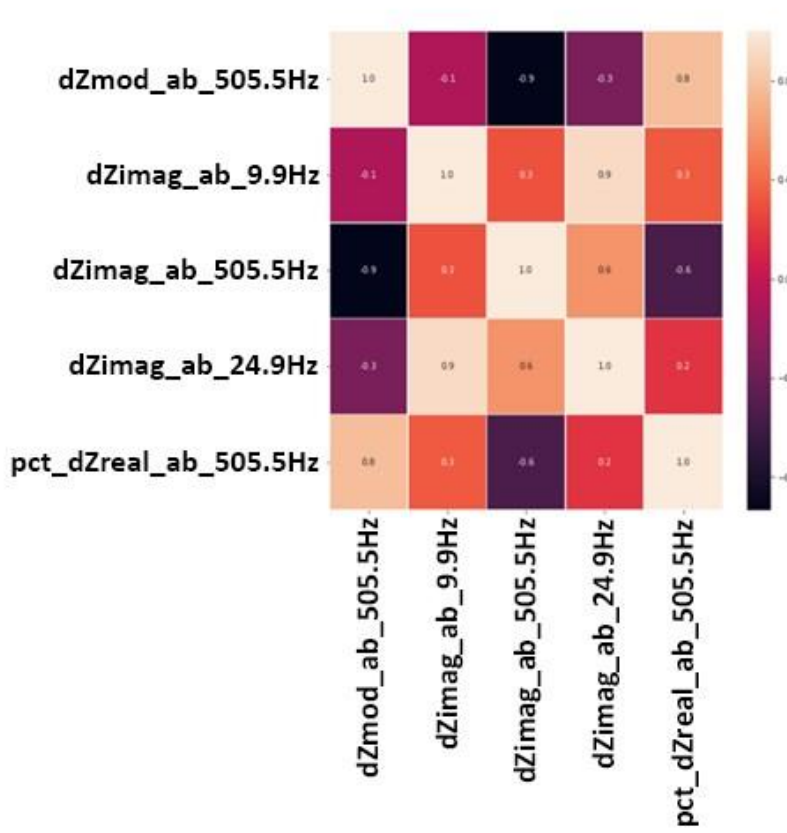




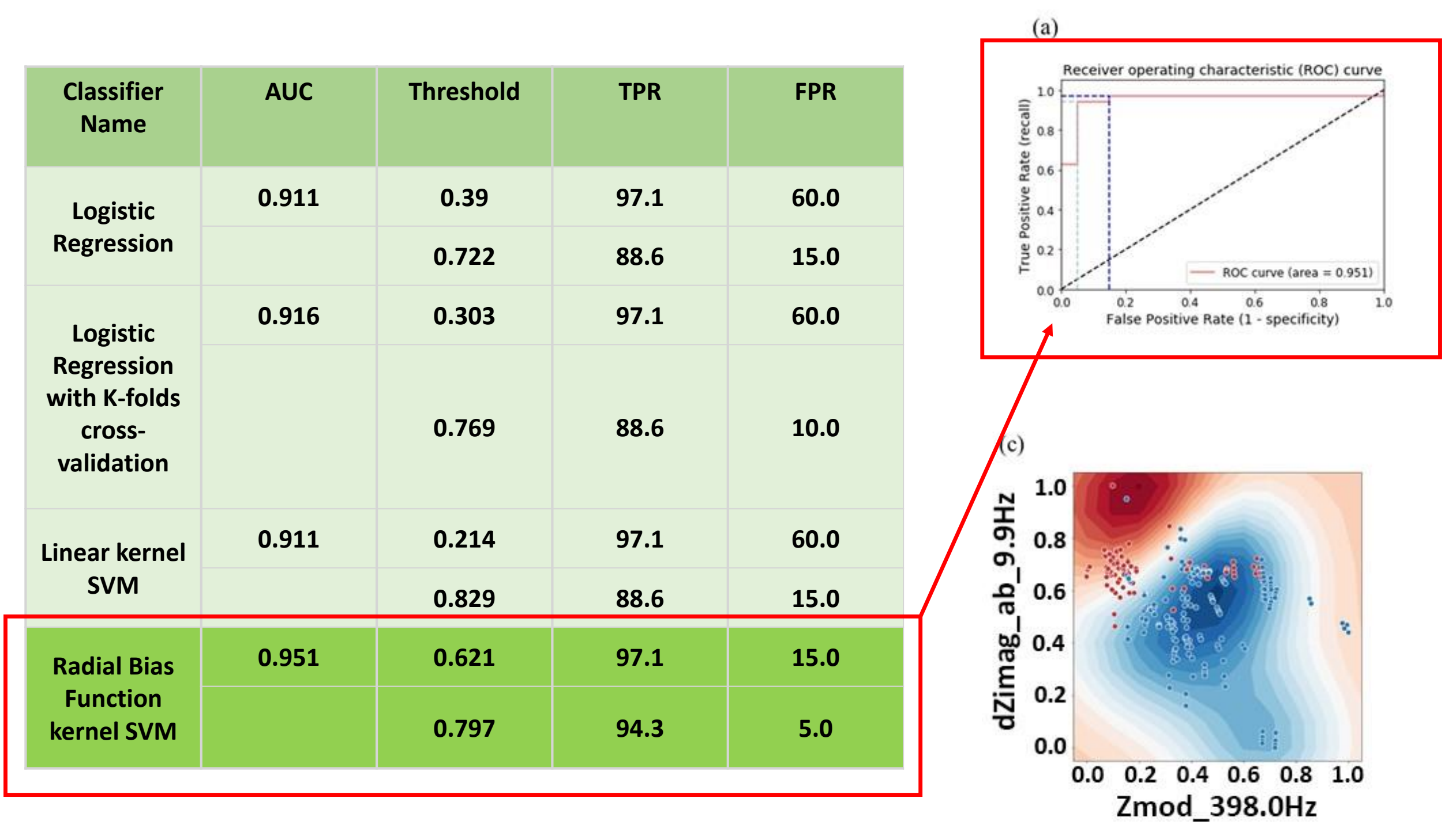

(b)
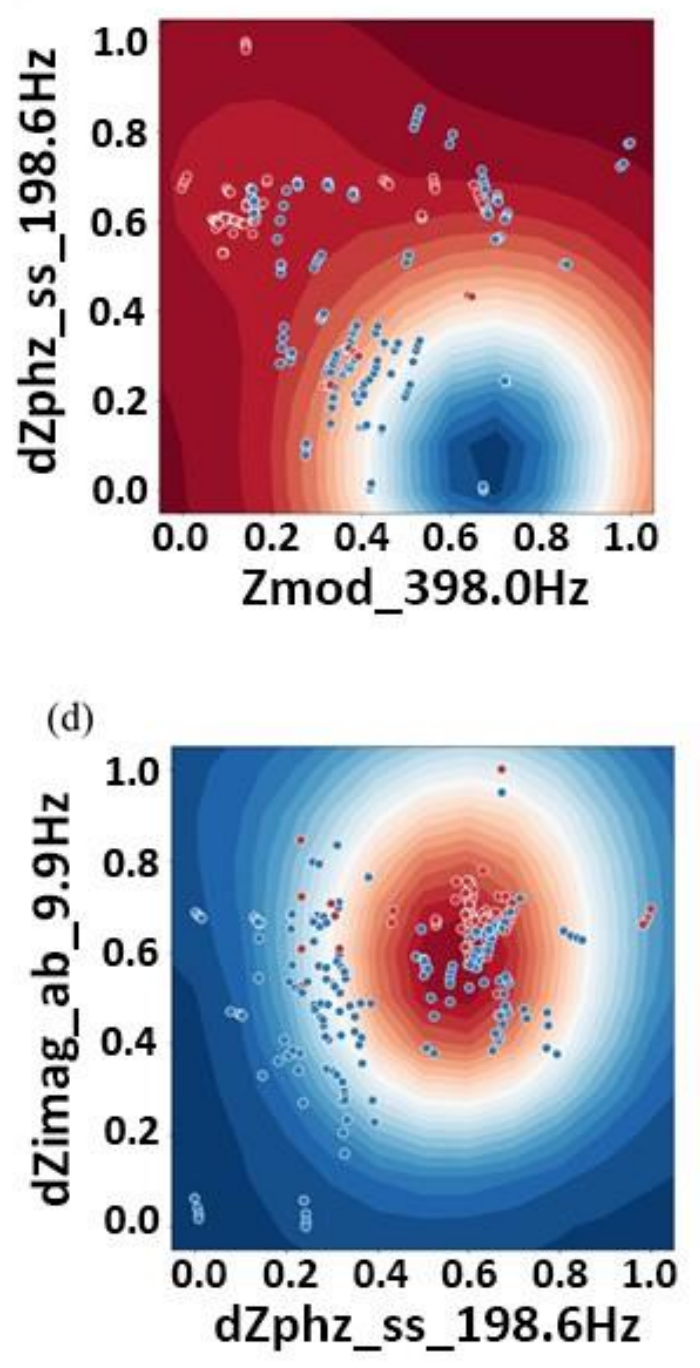
- This work utilizes non-faradaic EIS to rapidly and precisely detect the THC-BSA hapten spiked in human saliva with high specificity and sensitivity. (LoD: $100 \mathrm{ng} / \mathrm{mL}$ )

- A portable, battery-powered device interfaced with a one-time use saliva swab embedded with the THC detection sensor for easier and faster (<3-5 minutes) roadside testing when implemented using low-power EIS hardware.

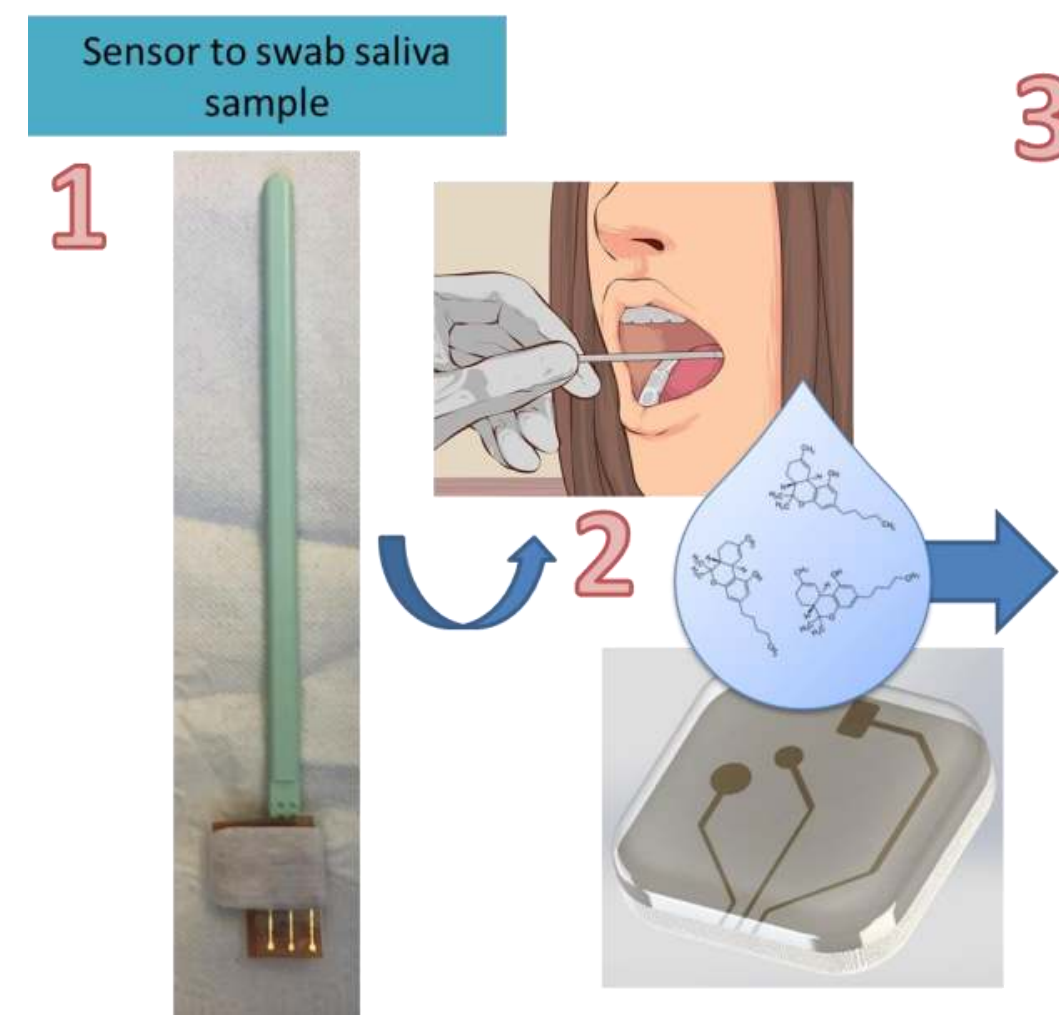

2. Sensing Platform

5

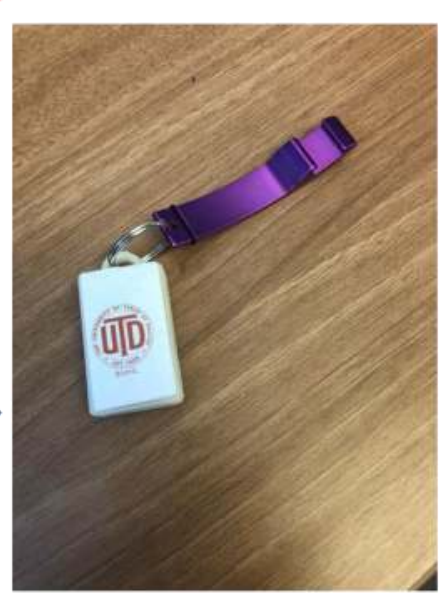

Sensor swab feeds into Electronic Interface.

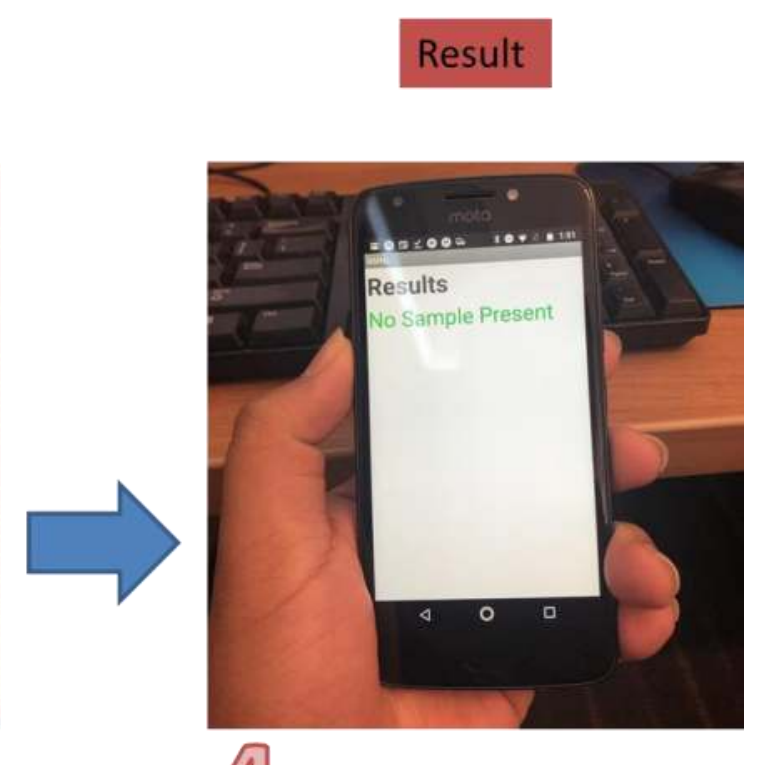

13 THC level readout

- Implementing a non-linear RBF kernel SVM algorithm to perform binary classification demonstrated a very high general performance $(A \cup C=0.951)$ at predicting the presence of $\mathrm{THC}$ within human saliva. 
- Volkow ND, Baler RD, Compton WM, Weiss SR. Adverse health effects of marijuana use. N Engl J Med. 2014;370(23):22192227. doi:10.1056/NEJMra1402309

- Stevenson, H., Bacon, A., Joseph, K.M. et al. A Rapid Response Electrochemical Biosensor for Detecting Thc In Saliva. Sci Rep 9, 12701 (2019). https://doi.org/10.1038/s41598-019-49185-y

- Hall, W. \& Degenhardt, L. Adverse health effects of non-medical cannabis use. Lancet (London, England) 374, 1383-1391 (2009).

- Hartman, R. L. \& Huestis, M. A. Cannabis Effects on Driving Skills. Clin. Chem. 59, https://doi.org/10.1373/clinchem.2012.194381 (2013).

- Statistics, H. 2014 - SAMHSA - NSDUH 2013 results. doi:NSDUH Series H-41, HHS Publication No. (SMA) 11-4658. (2013).

- Substance Abuse and Mental Health Services Administration (SAMHSA, Analytes and Their Cutoffs, Federal Register, November 25, 2008 (73 FR 71858), Section 3.4.

- Washington State,Liquor and Cannabis Board- THC limits in blood (DUI).

- Colorado State, Department of Transportation-Cannabis and Driving cut-off limits.

- Drummer OH. Drug testing in oral fluid. Clin Biochem Rev. 2006;27(3):147-159.

- D. Gieringer - Feb 2017 - Vsn 2 Feb 25, Cal NORML

- Phillips, J. A. et al. (2015) 'Marijuana in the Workplace: Guidance for Occupational Health Professionals and Employers: Joint Guidance Statement of the American Association of Occupational Health Nurses and the American College of Occupational and Environmental Medicine', Workplace Health \& Safety, 63(4), pp. 139-164. doi: 10.1177/2165079915581983.

- Sharma P, Murthy P, Bharath MM. Chemistry, metabolism, and toxicology of cannabis: clinical implications. Iran J Psychiatry. $2012 ; 7(4): 149-156$. 